Canadian Studies in Population, Vol. 34.2, 2007, pp. 191-215

\title{
An Analysis of Socio-Economic Strains and Population Gains: Urban and Rural Communities of Canada 1981-2001
}

\author{
Fernando Mata \\ Strategic Policy Research Directorate \\ Human Resources and Social Development Canada \\ Fernando.Mata@hrsdc-rhdsc.gc.ca
}

Ray D. Bollman

Agriculture Division

Statistics Canada

\begin{abstract}
Important demographic shifts have occurred in Canada in the last decades. As a consequence of these shifts, many geographical communities have won or lost substantial number of residents between 1981 and 2001. Using the CCS (consolidated census subdivision) data set of the Agriculture Division of Statistics Canada, the paper explores the linkages between socio-economic strains and population changes affecting communities in a variety of regional and provincial contexts. A total of 2,607 rural and urban consolidated census subdivisions were examined across five census periods. Quasi simplex structural equation models using unemployment, earnings and poverty as indicators were tested on a variety of communities located in various OECD regions and provinces. Although the predictive power of strains on population gains was found to be limited in the models, a higher level of strain was persistently found to be negatively associated with population gains regardless of regional and provincial groupings of communities. Socio-economic strains were also observed to be relatively stable over time across a variety of geographies.
\end{abstract}

Key Words: population gains, socio-economic strain, regions, urban-rural 
Fernando Mata and Ray D. Bollman

\section{Résumé}

D'importants changements démographiques ont eu lieu au Canada au cours des dernières décennies. Beaucoup de communautés traditionnelles géographiques ont donc vu leur population augmenter ou diminuer de manière importante entre 1981 et 2001. En s'appuyant sur les données de la SRU (subdivision de recensement unifiée) de la division de l'Agriculture de Statistique Canada, cet article explore les liens entre les tensions socio-économiques et les changements de populations qui ont affecté les communautés dans différents contextes régionaux et provinciaux. 2,607 subdivisions de recensement unifiées ont été examinées pendant cinq périodes intercensitaires. Des modèles structuraux linéaires quasi-simplexes d'indicateurs de chômage, du revenu et de la pauvreté ont été testés dans plusieurs communautés situées dans différentes régions et provinces OCDE. Bien qu'il ait été trouvé que le pouvoir prédictif des tensions dues aux gains de population est limité dans ces modèles, un plus haut niveau de tension a été lié de manière persistante et négative aux gains de population et ce, indépendamment des regroupements régionaux et provinciaux des communautés. Il a aussi été observé que les tensions socio-économiques reste relativement stable au fil du temps dans diverses régions géographiques.

Mots-clés: gains de population, tensions socio-économiques, régions, urbain-rural

\section{Introduction}

According to the general theory of community strain, communities characterized by socio-economic strains "block community member's abilities to achieve positive goals, creating a loss of positive stimuli, exposing members to negative stimuli and increasing overall deprivation" (Agnew, 1999:124). Socio-economic strain is seen here as a structural process which diminishes the quality of life of community residents by lowering their overall living, working and residential conditions. Strained communities experience a higher level of human and community capital depreciation (Hagan, 1994, PRI, 2002). Lack of jobs, lower earnings and limited local opportunities and rising poverty are typical symptoms of socio-economic strain. Individuals cope with these strains in different ways. Some residents attempt to change the place attributes and/or their individual characteristics to better cope 
while others simply leave the geographical areas affected by them. It is suspected that socio-economic strains may be one of the main reasons behind Canada's accelerated rates of urbanization, metropolitan concentration and regional economic inequalities in recent years (Bourne and Simmons, 2002)

While cataloging the major demographic shifts which occurred between 1981 and 2001, Mwansa and Bollman (2005) observed that those geographical communities (consolidated census sub-divisions or CCSs) that experienced regularly population gains between four inter-censal periods were often located within predominantly urban regions, smaller-city regions (i.e. intermediate regions) and/or rural metroadjacent regions. Predominantly urban regions (PUI's) displayed a net intercensal population gains of over 1 million individuals in the 15 years previous to the 2001 census while predominantly rural regions (PR's) displayed a pattern of decreasing gains over the same period; 365.1 thousand between 1986-91, 423.4 thousand between 1991-96 and only 39.6 thousand between 1996-2001 (see table 1). At the provincial level, while provinces such as Ontario, British Columbia and Alberta had substantial gains over the four intercensal periods, net gains were minimal and/or negative for provinces such as Atlantic Provinces and Saskatchewan. Some provinces displayed an erratic pattern over time. After experiencing net population gains consecutively in the first three intercensal periods Nova Scotia lost 2.4 thousand individuals between 1996-2001. Population losses observed between 1996-2001 were particularly palpable in the case of communities located in rural non-metro adjacent and rural northern regions (net loss of 72.9 and 19.1 thousand residents). Newfoundland and Labrador, Saskatchewan and New Brunswick lost 39.1, 13.5 and 10 thousand residents respectively. Population losses may have been more significant for the latter areas in view of the smaller average population sizes of the communities located within these geographies.

In their analysis, Mwansa and Bollman noted that communities which were typical population losers in the 20 year span of censal observations were characterized by higher levels of socio-economic strain. According to the authors, population growth was less likely to occur in areas characterized by higher unemployment, lower earnings and a "lower share of their aggregate income from earnings and investment income such as savings and/or investments and a higher share from social transfer income" (Mwansa and Bollman, 2005 p.20). Rural communities were challenged by a combination of depressed earnings and depopulation processes which seemed to persist over time. 
Fernando Mata and Ray D. Bollman

\section{Working Hypotheses}

Several questions may be raised about the relationships between strains and population gains for particular geographical regions in Canada: For instance: are unemployment, earnings and poverty-related indicators adequate measures of socio-economic strains affecting communities? Are these strains relatively stable over time? Are they good predictors of population gains or losses and vice-versa -are population gains and losses good predictors of community strain effects? What causal directional impacts may have been stronger over time: strain to population effects or population to community strain effects? What types of communities in the country are the more impacted by these processes?

Using the same 1981-2001 CCS dataset used by Mwansa and Bollman, the purpose of this paper was to empirically explore five working hypotheses linking socioeconomic strains to population gains. Working hypothesis were derived from Agnew's (1999) original theoretical strain framework linking community characteristics to social, economic, residential and crime outcomes. Briefly stated, these hypotheses were the following:

H1: Indicators such as unemployment, earnings and poverty will tap a common factor across time, that is, socio-economic strain;

$\mathrm{H} 2$ : Communities at higher levels of strains at one census point will remain at these levels at the next census point;

H3: Communities experiencing a high level of strain at one census point will tend to experience population loss between this point and the next point of observation;

H4: Population losses observed at a particular census point will contribute to increase levels of strain at the subsequent census point;

H5: The magnitude of the impact of strain on population gains or losses will vary across regional and provincial contexts.

In this paper, these five working hypotheses were integrated into an statistical model and explored through structural equation models which were applied to several regional and provincial groupings of consolidated census sub-divisions in 1981, 1986, 1991, 1996 and 2001. 


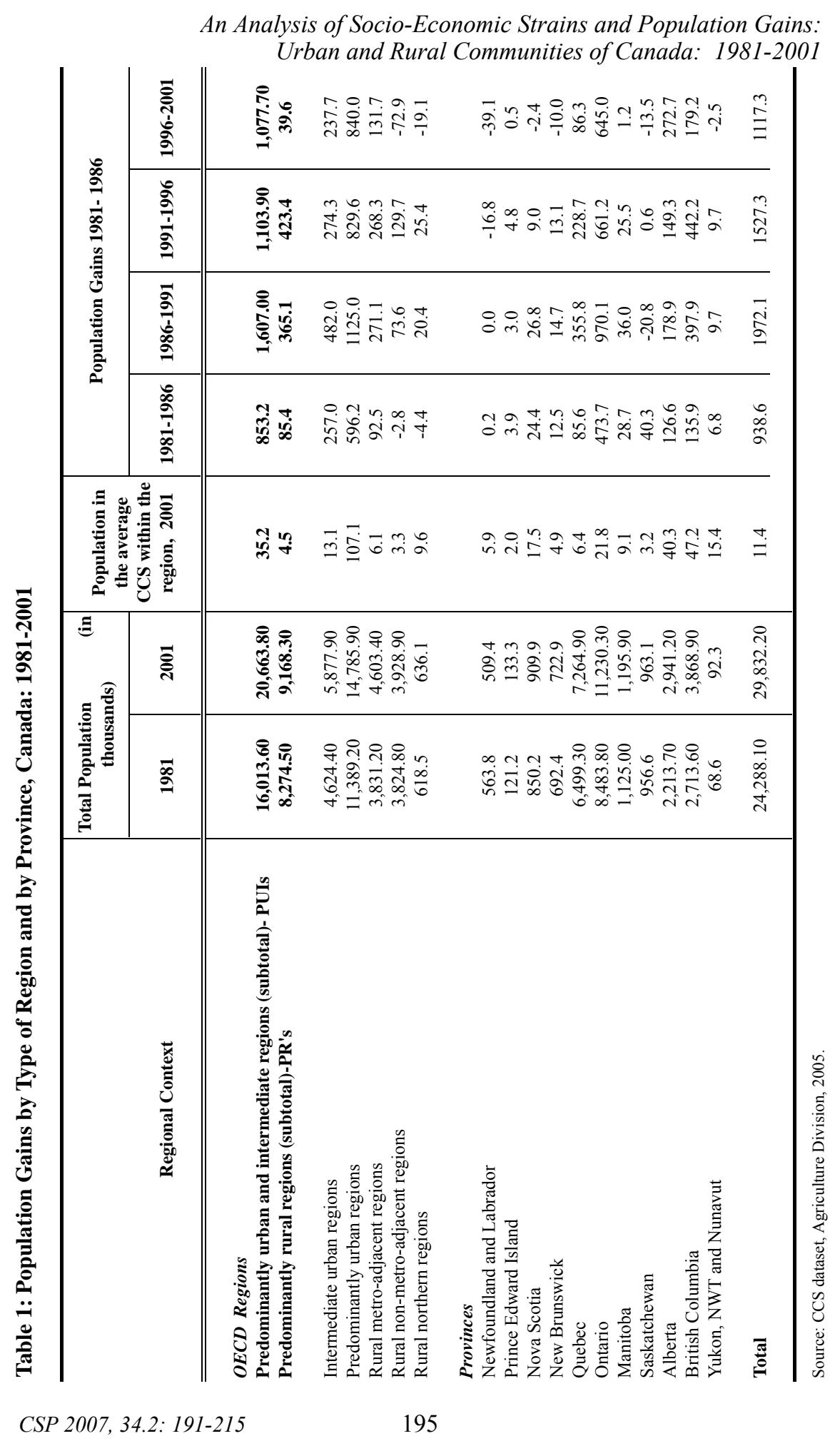


Fernando Mata and Ray D. Bollman

\section{Data Source}

The 1981-2001 CCS database of the Agriculture Division of Statistics Canada is the data source used for this analysis. It contains information on hundreds of demographic and socio-economic variables compiled for 2,607 consolidated subdivisions of Canada. In December, 2005, this database contained approximately 70 demographic, 66 employment, 33 income and housing and 21 education related variables.

The unique contribution of this dataset is that the variables are tabulated within constant boundaries (using 1996 CCS and CD boundaries) for five censuses: 1981, 1986, 1991, 1996 and 2001. Consolidated census sub-divisions represent a consolidation of two or more census sub-divisions (i.e. incorporated towns or incorporated municipalities) - the typical case is where an incorporated town is surrounded by an incorporated municipality and they are 'consolidated' for statistical purposes (Statistics Canada, 2002) . Regions are represented by census divisions which are intermediate geographic areas between the municipality (census sub-division) and the province level and usually represent counties, regional districts and regional municipalities.

CCSs of the dataset were classified according to their membership in OECD regions and Canadian provinces. OECD regions were defined using the Organization for Economic Co-operation and Development classification scheme based on the central the concept of the OECD "rural" community. An OECD rural region is defined here as geographical areas "with a population density less than 150 people per square kilometer" (OECD, 1994, du Plessis et al., 2001). These areas are distinguished in terms of their share of population living in OECD "rural" communities: In this study five regions of community membership were identified: a) Predominantly urban regions: where less than $15 \%$ of the population lived in a "rural community"; b) intermediate urban regions where between $15 \%$ and $50 \%$ of the population lived in a "rural community" and, c) predominantly rural regions where more than $50 \%$ of the population lived in a "rural" community. To recognize diversity of the latter region, Statistics Canada identified three sub-groups using a Beale code approach: those rural adjacent to metropolitan centres, those rural not adjacent to metropolitan centres and rural Northern regions. For more information on the OECD territorial scheme and definitions of rural, see OECD (1994).

The majority $(78 \%$ or 2,020$)$ of communities in the dataset were located in OECD rural areas (rural metro adjacent, rural non-metro adjacent and Northern) while the remaining $(22 \%$ or 587$)$ were located in urban areas (intermediate and predominantly urban). The most numerous ones were those classified as rural non- 
metro adjacent $(46 \%$ or 1,193$)$ followed by rural metro-adjacent $(29 \%$ or 761$)$, intermediate urban region (17\% or 449$)$, predominantly urban (5\% or 138$)$ and rural Northern communities ( $3 \%$ or 66$)$. In terms of provincial location of CCS's these were the following: Newfoundland (3\% or 87), Prince Edward Island (3\% or 68 ), Nova Scotia ( $2 \%$ or 52 ), New Brunswick (6\% or 148$)$, Quebec ( $44 \%$ or 1,143 ), Ontario ( $20 \%$ or 515$)$, Manitoba ( $5 \%$ or 131 ), Saskatchewan ( $12 \%$ or 302$)$, Alberta ( $3 \%$ or 73 ) and British Columbia ( $3 \%$ or ). CSS's from the Northwest Territories, Nunavut and the Yukon accounted for $0.2 \%(\mathrm{~N}=6)$ and due to their small sample size were excluded from the analysis.

\section{Structural Equation Model}

By "freezing" the boundaries of census sub-divisions and collecting community indicators at five census points, the CCS dataset of Agriculture Canada presents quasi-longitudinal survey properties whereby repeated measures are obtained from the same units over time. This type of survey design is amenable to various types of multivariate analysis. Structural equation modeling , however, was chosen as the ideal multivariate tool due to the combination of its measurement and structural properties in dealing with linkages between observed and unobserved (latent) variables implied by hypothesized causal structures.

The analytical approach adopted here is that socio-economic strain is not a directly observable phenomena and as such it constitutes a latent variable. Unemployment, earnings and poverty related indicators, which are chosen for this analysis, constitute essential core variables regularly used to identify socio-economic conditions of disadvantage in rural and urban areas (Lee 2000, Feser and Sweeney, 2003). These types of indicators depict both absolute dimensions of deprivation or hardship allowing to determine the relative socio-economic standing of a particular geographical area or community with respect to others.

The path diagram of the quasi simplex structural equation model (QSEM) which is used for the analysis is presented in chart 1. The QSEM model was initially developed by Karl Jorëskog's (1970) and further developed by Wheaton et. al. (1977). The QSEM model is particularly useful in cases where covariance structures are generated by variable(s) repeatedly measured on the same units over several occasions (e.g. at five census periods). The model has been described as a first order non-stationary autoregressive process which allows measurement errors across indicators. The mathematical formulation of the QSEM model may be expressed in terms of the following defining equations: 
Fernando Mata and Ray D. Bollman

$$
\begin{aligned}
& \mathrm{Y}_{\mathrm{i}}=\eta_{\mathrm{i}}+\delta_{\mathrm{i}}(1) \\
& \mathrm{X}_{\mathrm{l}==} \beta_{\mathrm{i}} \eta_{\mathrm{i}-\mathrm{k}}+\mathrm{p}_{\mathrm{i}}(2) \\
& \eta_{\mathrm{i}}=\beta_{\mathrm{i}} \eta_{\mathrm{i}-\mathrm{k}}+\beta_{1} \mathrm{X}_{1}+\zeta_{\mathrm{i}}(3) \text { where: }
\end{aligned}
$$

$\mathrm{Y}_{\mathrm{i}}$ is the ith indicator of socio-economic strain, $\eta_{i}$ is an unobserved scale of socio-economic strain, $\delta_{\mathrm{i}}$ is the measurement error of the ith indicator of socio-economic strain, $\beta_{i}, \beta_{1}$ are structural parameters,

$X_{1}$ is an observed covariate or predictor (i.e. population gains),

$\mathrm{p}_{\mathrm{i}}$ is the disturbance associated with the prediction of $X_{1}$,

$\zeta_{\mathrm{i}}$ is the structural disturbance associated with the prediction of the scale of socioeconomic strain and,

$\mathrm{k}=$ time lag between successive observations (in this case $\mathrm{K}=5$ for five census points)

The latent strain variables in the path diagram of figure 1 are named S1981, S1986, S1991, S1996 and S2001 (represented by darker circles) while observed ones (X's or population gains) as g81_86, g86_91 and g96_01 (represented by darker squares). The symbols u1,e1, 11...u5,e5,15 (Y's) represent indicators of unemployment, earnings and poverty, respectively measured at times $1=1981$, $2=1986,3=1991,4=1996$ and $5=2001$. Structural disturbances associated with the predictions of latent variables in the QSEM model are represented by the symbols $\mathrm{z} 1$ to $\mathrm{z} 5$ while those disturbances of population gain indicators by $\mathrm{p} 1$ to $\mathrm{p} 4$. Delta variables $\mathrm{d} 1$ to $\mathrm{d} 15$ (unexplained variances of latent variable indicators) are represented by the symbols $\mathrm{d} 1$ to $\mathrm{d} 15$.

The measurement part of the model (left hand side moving upwards) provides information on the reliability of indicators in terms of tapping latent variables. The structural part of the model (right hand side moving upwards) represents impacts of a lagged latent variable (strain) on one another as well as the impacts of economic strain on population gains (and vice-versa) across the five time points of observation

The QSEM model, which incorporates the five working hypotheses, contains three types of paths of interest: strain-to-strain paths $(A, B, C, D)$, strain-to-population paths $(\mathrm{E}, \mathrm{F}, \mathrm{G}$ and $\mathrm{H})$ and population-to-strain paths (I,J,K and L). While coefficients related to the first set of paths represent the degree of stability in the strain construct across time, the second and third set of paths assess the directionality and magnitude of impacts between population and economic strain variables. It was anticipated that most communities already strained in 1981 would continue to do so over subsequent census points, that is, in symbols: $(A, B, C, D)>0$. Similarly, strained communities would experience population losses (negative gains) between 
census periods or in symbols that $(\mathrm{E}, \mathrm{F}, \mathrm{G}, \mathrm{H})<0$. Also anticipated was that, given the assumption of stability of strain, population (losses) will have an impact on community strains observed at subsequent periods or in symbols that $(\mathrm{I}, \mathrm{J}, \mathrm{K}, \mathrm{L})$ would also be $<0$.

For this analysis, the traditional goodness of fit measures associated with structural equation models such as the likelihood ratio $\mathrm{X}^{2}$ and RMSEA statistics are used as "exploratory" tools (Bollen and Long, 1993) to identify the constancy in the direction, size and statistical significance of model parameters in a variety of regional and provincial contexts and not for modeling purposes.

Results of QSEM models are presented here in graphical and tabular form. Model parameters were estimated by the method of full information maximum likelihood using the software AMOS-5 (Arbuckle and Wothke,1999).

The variables of QSEM models were defined as follows:

\section{Observed Variables: Population Gains}

Population gain indicators: defined as net differences in non-institutionalized population size counted between successive census periods (positive and negative counts of individuals). In the QSEM model these are respectively represented by the symbols: g81_86 (Population gain 1981-1986), g86_91 (Population Gain 19861991), g91_96 (Population Gain 1991-1996) and g96_01 (Population Gain 19962001). The means (m) and standard deviations (s) for these variables were the following:

g81-86: $\mathrm{m}=+360.0, \mathrm{~s}=2,721.8$;

g86_91: $\mathrm{m}=+756.5, \mathrm{~s}=4,104.4$;

g91_96: $\mathrm{m}=+585.9, \mathrm{~s}=3.328 .6$;

g96_01: $\mathrm{m}=+428.6, \mathrm{~s}=3,863.0$.

\section{Latent Variables: Socio-Economic Strains}

Socio-economic strain variables for the five census periods $(1981,1986,1991$, 1996 and 2001) were measured by three indicators:

1) u- the unemployment rate in the labour force aged 15 years old and over in the CCS; 
2) e- an earnings disadvantage index represented by the inverse of the logarithm of earnings (per person 25 to 54 with some earned income) x 100 in the CCS;

3) 1- the percentage of individuals in economic families living under the poverty cut-off rate in the CCS.

The numbers 1 to 5 following the u-e-1 symbols represent the census time points of observation: $1=1981,2=1986,3=1991,4=1996$ and $5=2001$.

The unemployment rate was defined in the standard way and calculated as the number unemployed divided by the number employed plus the number unemployed aged 15 years old and over The earnings disadvantage index was based on the average earned income was calculated for persons 25 to 54 with some earned income (current dollars) including wage and salary income, unincorporated selfemployment net farm income and unincorporated self-employment net income from operating a business and/ or professional practice. This age cut was chosen as the most appropriate in order to capture a labour force segment less influenced by post-secondary and pre-retirement activities during their working cycle. In order to normalize its statistical distribution and ensure coherence with the other strain indicators, earnings were transformed using an inverse-logarithm transformation. The poverty indicator (which is used as measure of low income in families) referred to the percentage of persons in economic families with PRE TAX income below the low income cut-off. Given that the LICO indicator was not calculated for individuals living on Indian Reserves, the category "LICO not applicable" was excluded from both the numerator and the denominator of calculations.

Some changes in the means of indicators were noticeable across time. In terms of unemployment rates, for instance, these rates jumped from an average of $17 \%$ to $21 \%$ between 1981 and 2001 for the communities located in rural northern regions and from $22 \%$ to $33 \%$ for the average community in Newfoundland and Labrador. The earnings disadvantage ratio experienced a -.5\% drop between 1981 and 2001 when averaged across all OECD regions. The poverty cut-off measure experienced an overall drop of $4.8 \%$ across OECD regions reflecting some degree of improvement over time. The only exception to this generalized drop in the values of the poverty indicator was British Columbia communities which experienced a net increase of $1.5 \%$.

Average correlations between strain indicators across census periods were the following: $1981=+0.32,1986=+0.39,1991=+0.34,1996=+0.36$ and $2001=+0.49$ (all statistically significant at the .01 level, see table A-1). Over time, correlations of the earnings indicators with the LICO ones were found to be stronger compared to between the former ones and unemployment rates. 
An Analysis of Socio-Economic Strains and Population Gains: Urban and Rural Communities of Canada: 1981-2001

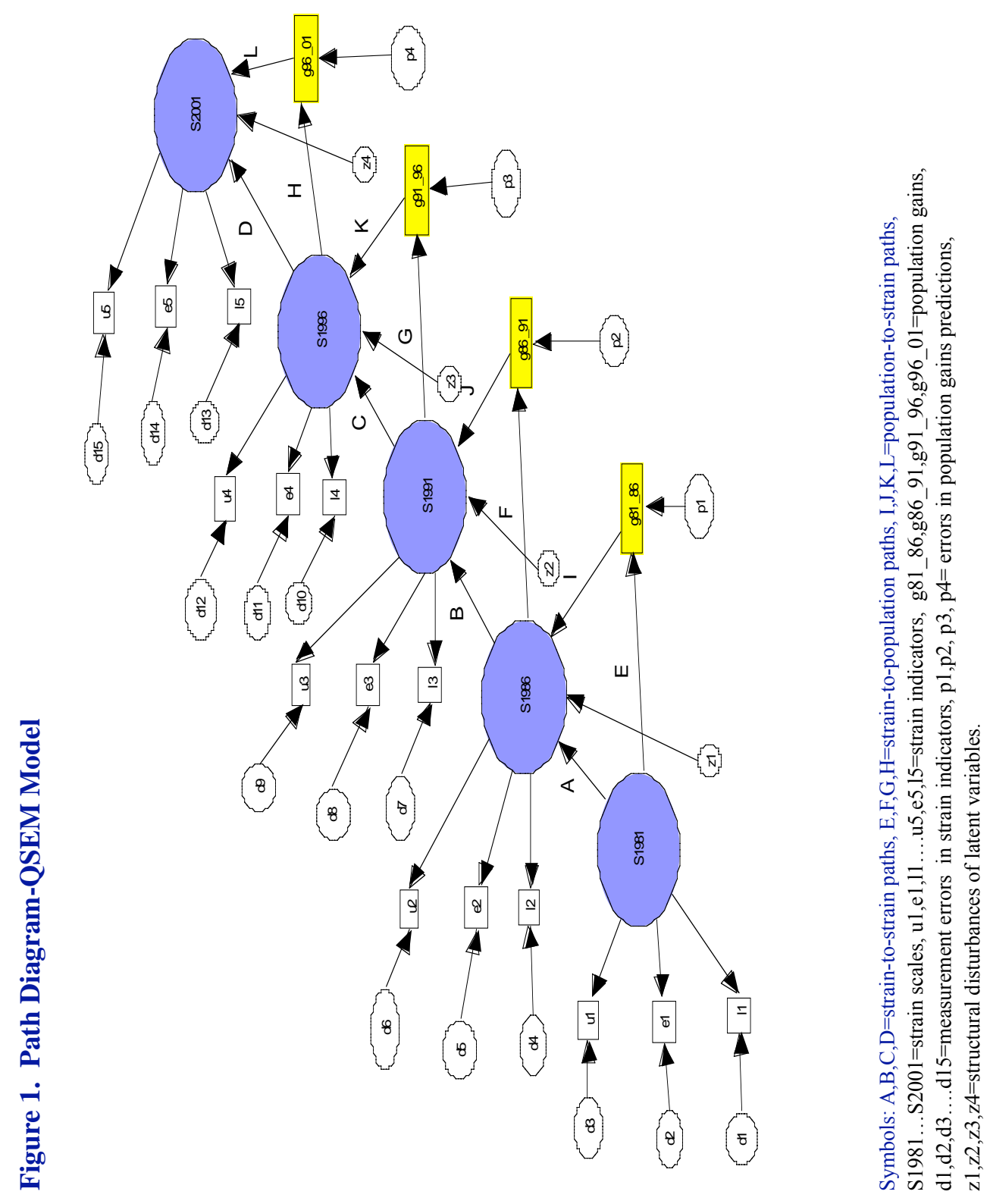


Fernando Mata and Ray D. Bollman

\section{Results}

\section{Overall Model}

The overall fit of the QSEM model (urban and rural communities) produced a $\mathrm{X}^{2}$ statistic of 23,779.3 with 144 degrees of freedom. All parameters in the structural equation model were found to be statistically significant at least at the .05 level. The RMSEA index obtained was .251, reflecting important discrepancies between observed and implied variance-covariances matrices Modification indices suggested that improvements to the model were to be made by introducing correlations of the population gain disturbances ( $\mathrm{p}$ 's), reducing the $\mathrm{X}^{2}$ statistic by $53 \%$ and reducing the RMSEA index to .175 . This modeling route was not undertaken, however, in order to preserve the simplicity of the model and avoid introducing extra parameters in the context of a limited number of observations by community groupings.

Using unemployment indicators as reference variables, overall the model extracted a strain latent variable with a mean of 0 and variance of 30.06 points in 1981 (S1981). Net from any population gains, every point of the S1981 strain scale approximately raised 1.3 points of the S1986 one. While less stability was observed between 1991 and $1996(.45)$, the greatest strain point returns were observed for the period 1996-2001: 1.94 points per 1 point in the preceding period. Examination of the strain-to-population paths $(\mathrm{E}, \mathrm{F}, \mathrm{G}$ and $\mathrm{H})$ revealed that increases of strain points meant population losses (negative gains) of different magnitudes across census periods. In the period 1981-86, for instance, one strain point meant the loss of an average of 96 residents for a particular CCSD. These population losses were 158 individuals in 1996-91, 134 in 1991-96 and 263 in 1996-2001. Strain scores, however, explained only between $4-7 \%$ of the variances of population gains across census periods. Population-to-strain coefficients (paths I, J, K and L) were found to be very small in magnitude though statistically significant.

\section{Models for Urban and Rural Communities}

Figures 2 and 3 present paths of unstandardized coefficients of QSEM models for urban (PUIs) and rural communities (PRs) while figures 4 and 5 display standardized ones. In the latter figures, $\mathrm{R}^{2}$ ' $\mathrm{s}$ for each predictive equation are found at the top of circles (latent variables) and squares (observed variables).

Comparing model fits, the QSEM rural model had a slightly better fit $(\mathrm{RMSEA}=.209)$ compared to the urban one $(\mathrm{RMSEA}=.274)$. The variance of the latent variables was larger in the case of rural areas (39.96 points) compared to 
An Analysis of Socio-Economic Strains and Population Gains: Urban and Rural Communities of Canada: 1981-2001

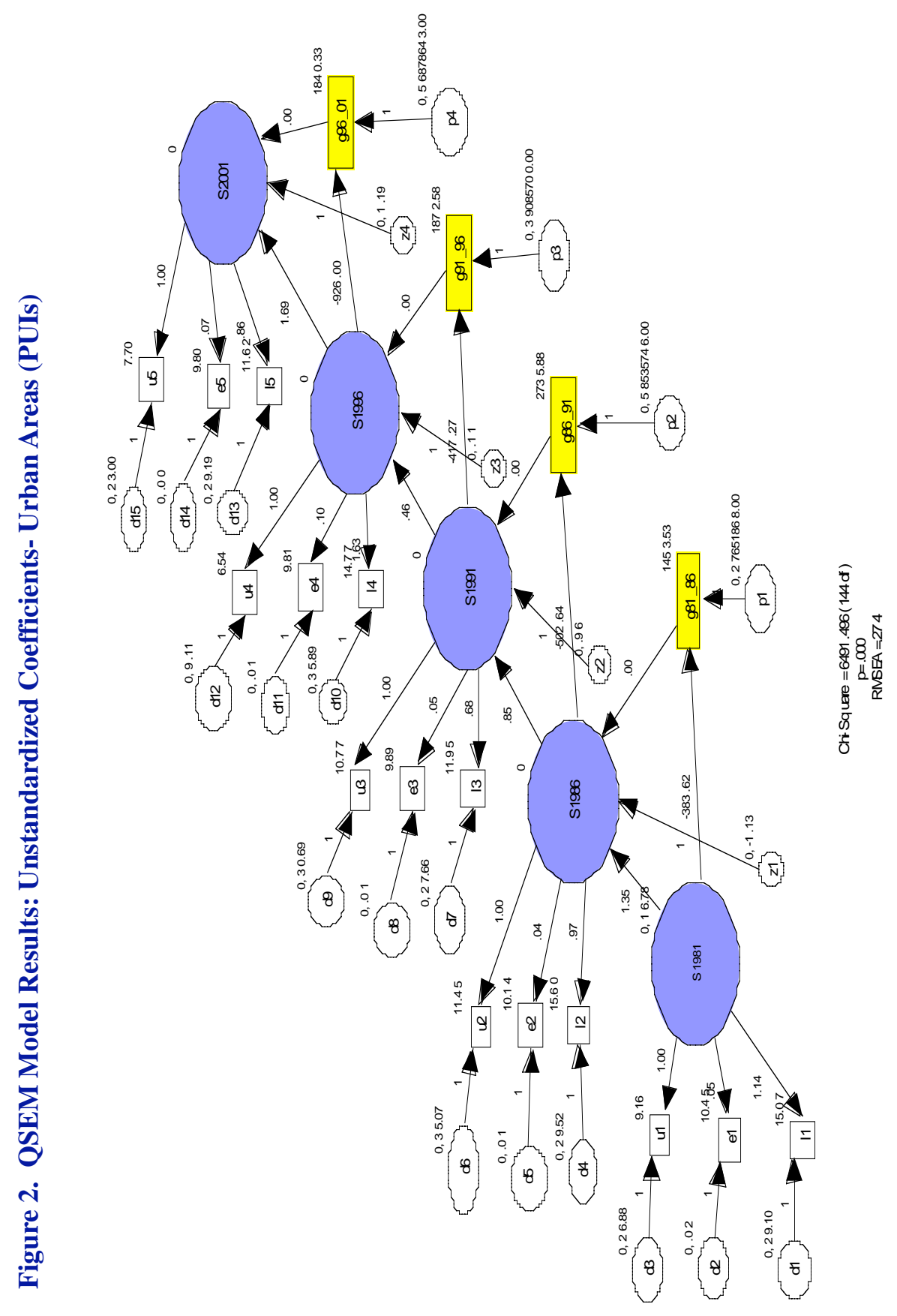


Fernando Mata and Ray D. Bollman

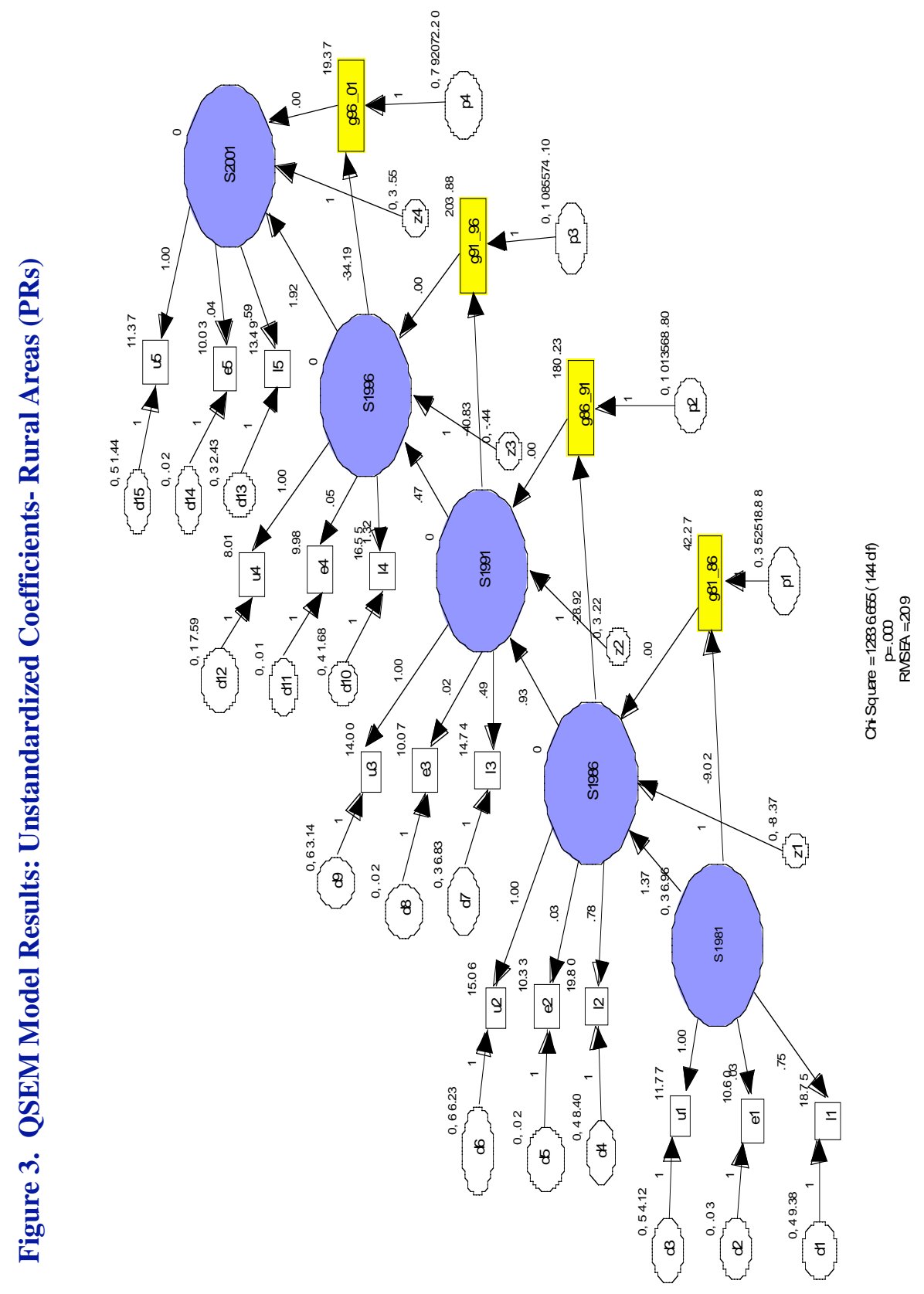

CSP 2007, 34.2: 191-215 
An Analysis of Socio-Economic Strains and Population Gains:

Urban and Rural Communities of Canada: 1981-2001

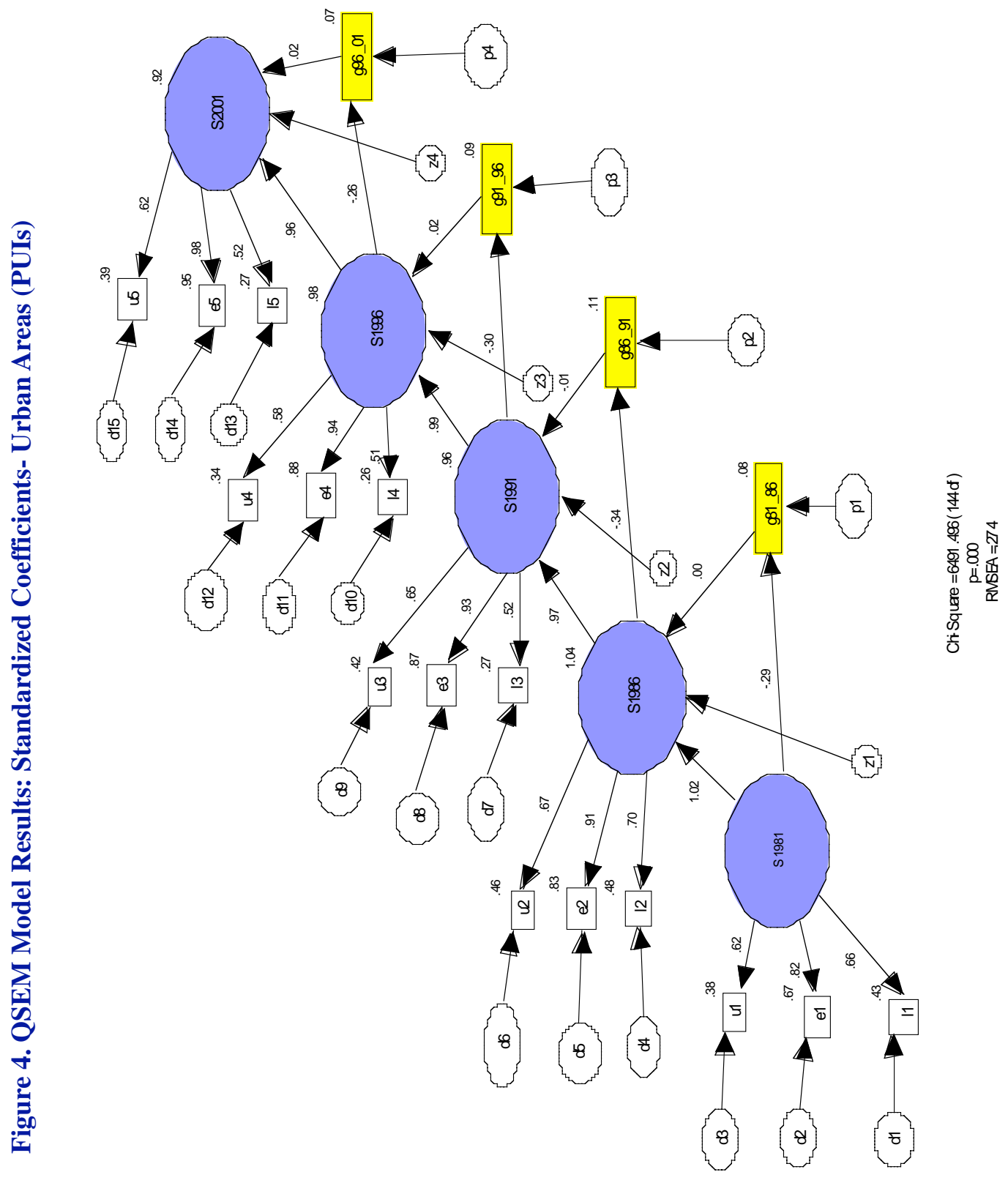


Fernando Mata and Ray D. Bollman

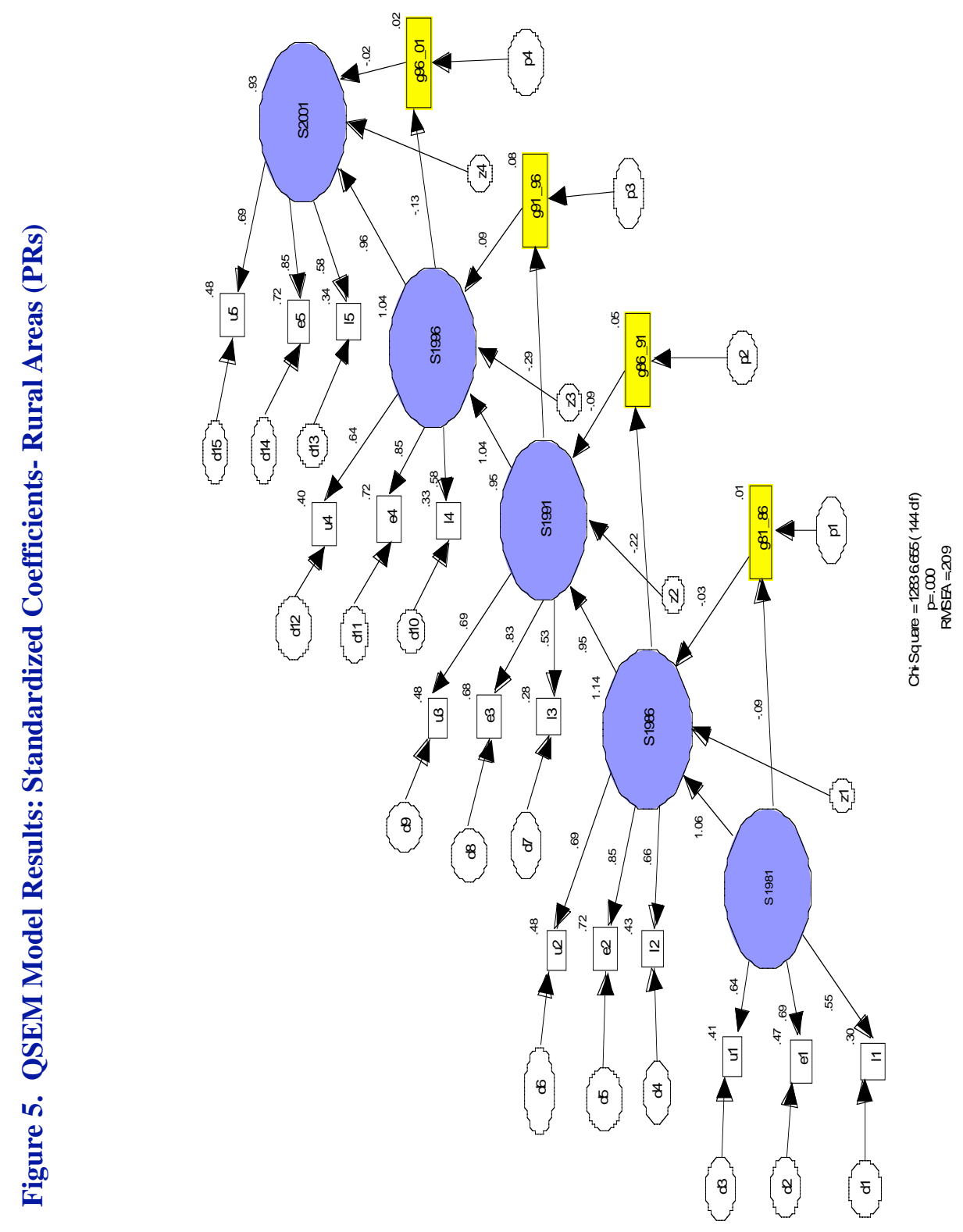


An Analysis of Socio-Economic Strains and Population Gains:

Urban and Rural Communities of Canada: 1981-2001

urban areas (16.78 points), For urban areas, each extra strain point was associated with a loss of 364 residents in the period 1981-86, 503 within 1986-91, 417 within 1991-96 and 926 within 1996-2001. The later period was the more costly for both predominantly urban and intermediate urban areas. The corresponding numbers for rural areas were as follows: loss of 9 residents in the period 1981-86, 28 in 198691, 41 in 1991-96 and 34 within 1996-2001. These population losses may be significant in some rural communities taking into consideration the smaller average population sizes of rural areas (approximately 6.1 thousand in rural metro adjacent, 3.3 thousand in rural- non metro adjacent and 9.6 in rural Northern regions).

Standardized coefficients of the measurement part of QSEM suggested that the three strain indicators were moderately reliable in tapping the strain construct. This is suggested by the relative size of $\mathrm{R}^{2}$ of the individual variances of indicators explained by latent variables. The most reliable indicator of strain across time was the earnings disadvantage ratio indicator which displayed coefficients ranging from .67 to .95 across urban areas and .47 to .72 across rural areas. The least reliable one was the LICO poverty indicator which displayed coefficients ranging from .27 to. 48 across urban areas and .28 to .43 across rural ones.

The most important finding of urban and rural models, however, was the low predictive power that socio-economic strain variables had on population gain ones over census periods. In urban areas, only 7 to $11 \%$ of the population gains/loss variance was explained by predictors and only $1-8 \%$ in rural ones.

Strain-to-population effects were observed to be stronger in predominantly urban areas compared to rural areas (approximately 2.7 times larger than the latter between 1981-86, 1.7 larger between 1986-91,1.2 larger between 1991-96 and 1.6 larger between 1996-2001). A unit change in the standard deviation of the strain score produced a -.29 point drop in the standard deviation of the population gain/loss variable between 1981-1986 in urban areas, a -.34 point drop between 1986-1991, a -.30 point drop between 1991-1996 and a -.26 point drop between 1996 and 2001. The corresponding point drops in standard deviations of the population gain/loss variables in rural areas were: $-.09,-.22,-.29$ and -.13 .

\section{Models for Communities in OECD Regions and Provinces}

Selected paths coefficients of QSEM models for communities in various OECD regions are presented in Table 2 . The best model fit corresponded to communities located in predominantly urban intermediate regions (RMSEA index $=.292$ ) while the poorest fit was evident for predominantly urban areas (RMSEA index $=.411$ ). Stability coefficients (strain-to-strain standardized paths) ranged between .69 and .93 across the OECD regions revealing moderate and/or strong stability of strain 
scores over time. Again, strain scores had limited explanatory power over population gains (less than $10 \%$ of explained variance accounted across groupings).

Selected paths coefficients of QSEM models for communities located in the various Canadian provinces are presented in Table 3 . The best model fit corresponded to communities located in the province of Manitoba (RMSEA index=.338) and the poorest for communities located in Ontario and Alberta+British Columbia (RMSEA indices of +.520 and .526 respectively). A higher variability of strain scores across time was observed for communities located in the province of Saskatchewan. For communities located in Saskatchewan, residual variances of strain variables remained substantial ( $50 \%$ or more) revealing perhaps some variety in the time trajectories of strain scores across communities located in this geographical area.

Subsequent data analysis of strain scales over the 1981-2001 period revealed also that socio-economic strains appeared to increase moving east across Canada. CCSs located in Newfoundland and Quebec displayed the highest levels of strain in most categories across census periods while CCSs located in New Brunswick were among the most noticeable in predominantly urban regions. Among CCSs located in predominantly urban areas, persistent higher strain scores were observed for Saint John (New Brunswick) and Quebec City (Quebec) throughout the 1981-2001 period. These geographical areas have lost a substantial number of residents in the last decade.

\section{Conclusion}

Following the steps of Mwansa and Bolman's demographic analysis of recent population shifts and using census consolidated sub-division data from the Agriculture Division of Statistics Canada, this study explored linkages between socio-economic strain and population gains in Canada. This analytical task was accomplished by testing several structural equation models which were applied to community data grouped into OECD regions and provinces. These models provided valuable information on reliability aspects as well as direction, size and statistical significance of model paths connecting socio-economic strains to population gains.

Although the predictive power of strain on population gains was limited (on average $10 \%$ of explained variance), strains were consistently found inversely related to population gains in a variety of regional and provincial contexts. Strainto-population effects (paths E, F,G and H) were substantially stronger than population-to-strain effects (paths I,J,K and L). The latter paths were generally found either small in magnitude and/or statistically not significant. The time 
An Analysis of Socio-Economic Strains and Population Gains: Urban and Rural Communities of Canada: 1981-2001

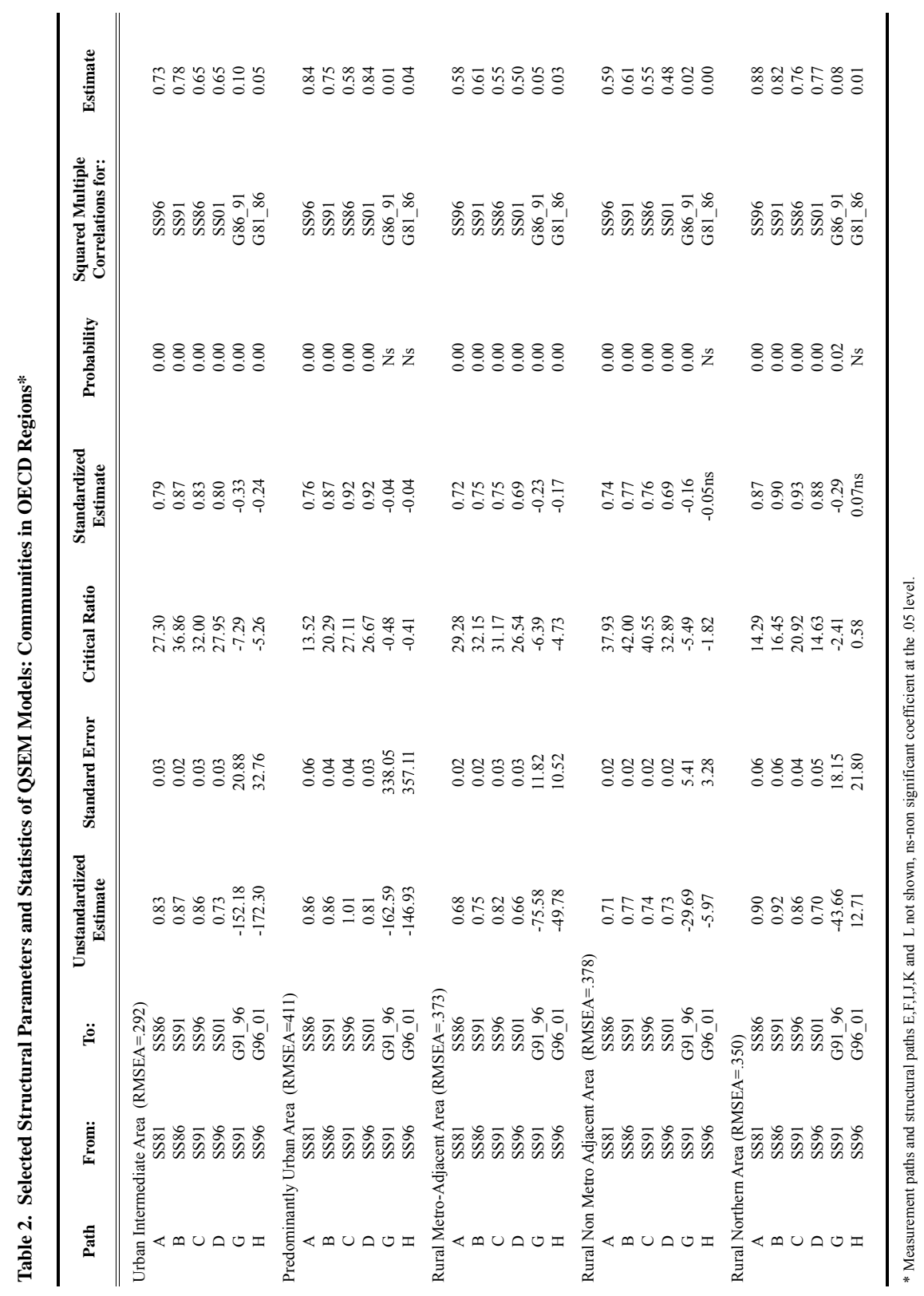


Fernando Mata and Ray D. Bollman

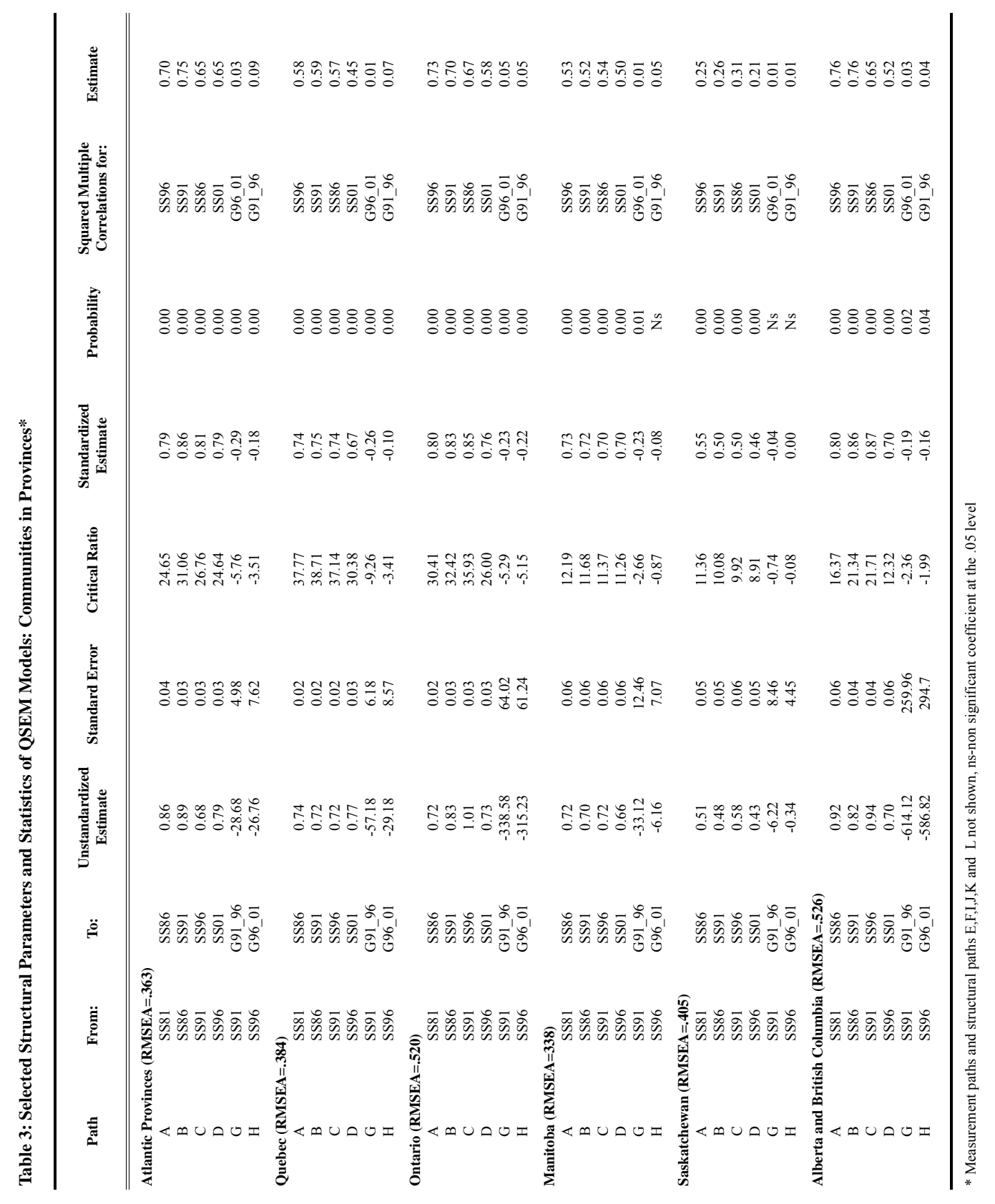


stability of strain was more pronounced within communities located in predominantly urban areas and rural northern areas and less so in rural non-metro adjacent ones as well as those located in the provinces of Saskatchewan. In terms of reliability criteria, earning related indicators of strain were found to be more useful than unemployment and poverty ones across the five time points of observation.

The strain phenomena proved to be a difficult phenomenon to measure as suggested by the presence of measurement error. This was suggested by the moderate-to-high average factor loadings (.51 and higher) and the indicators' variances still left unexplained by the latent strain constructs $\left(1-\mathrm{R}^{2}\right)$ in the QSEM models. This measurement pattern was observed across community types and five censal points studied. For both urban communities and rural communities, higher and more consistent reliabilities were displayed by earnings indicators compared to the unemployment and poverty ones. Although the dimensionality of the strain concept more clearly pivoted on earnings disadvantage related domains, a brief inspection of the magnitudes of the factor loadings and the reliability coefficients showed that unemployment and poverty domains were still significant constituents of the strain constructs. Further research has to be undertaken in this area.

Despite the benefits of constancy placed on the geographical boundaries of the CCSs, it is hard to determine with some degree of precision if, by leaving their previous places of residence, individuals may in fact have left an area of higher level of strain for another one of a lower one. It is likely that many migrants who have moved from one suburban or rural fringe did so within the geographical confines of a larger urban agglomeration. A correlational analysis focusing on the spatial distribution of strain (i.e. kernel densities) and associated covariates such as population movements offer a promising avenue to explore further this interesting research subject matter.

The present analysis suggests that socio-economic strains may not the only type of community strains presently affecting Canadian communities. Strains product of the community's resource base reflected in the type of industrial configuration and employment structure of the locality may also be important in this regard. In rural Canada, for instance, the introduction of labour-saving technologies such as those present in fishing, lumbering, mining and farming industries combined with the lack of capacity of these communities to find something new to export - creates excess labour which is likely to be transferred elsewhere. Previous multivariate analysis of census data has already revealed that the introduction of indicators related to dominant employment structures in communities substantially enhance the explanatory power of statistical models attempting to systematically relate economic performance, regional disparities and population shifts in Canada (Alasia, 2003; Alasia and Rothwell, 2003). 
Fernando Mata and Ray D. Bollman

It is important also to pause and briefly reflect on the findings of the study in terms of the broader context of regional growth and the present urban-rural system networks and flows (i.e. capital, goods and people) that exist in Canada. Regardless of the relative position that communities had in the urban-rural hierarchy, the phenomenon of socio-economic strain showed resiliency and was capable of reproducing itself over time creating "cumulative" effects even in the polar cases of this continuum such as communities located within large metropolitan areas as well as those located in rural Northern regions. Some of these communities have most likely undergone cycles of high levels of strain on a more permanent basis than others. Variations in these cycles may be responsible why there is an apparent division made between those who were typical population "winners" (e.g. Alberta, Ontario and British Columbia) and those who were typical population "losers" (Atlantic Provinces and parts of Quebec) during 1981 and 2001. As socioeconomic strain held its grip on various types of communities, entire regions surrounding and/or containing them may have accentuated their patterns of population decline, rapid aging of the resident population and/or substantial declines in their workforce as new improved technologies are being introduced.

The loss of valuable residents (e.g. rural youth) are having major implications of the relocation of health, educational and local services, local housing conditions and fluctuations in real state values.

In view of these impacts, different levels of government in Canada need to be more creative in terms of making adequate investment decisions, promoting targeted community well-being as providing services in a cost-effective manner in both urban and rural areas. This approach includes offsetting negative impacts of socioeconomic strains by creating economic opportunities in rural areas and ensuring at the same time that urban areas are not over-pressured by the arrival of new waves of workers seeking improvements to the quality of their lives.

\section{Acknowledgements:}

The first version of paper was presented to Statistics Canada Socio-Economic Conference, May 16, 2006, Ottawa, Ontario. The views presented in this paper reflect the view of the authors and do not reflect necessarily those of Human Resources and Social Development Canada (HRSDC) nor Statistics Canada (SC). The authors would like to thank Roland Beshiri and Alessandro Alasia of the Agriculture Division of Statistics Canada, Mireille Laroche of HRSDC as well as professor Leslie Hayduk (University of Alberta) for their suggestions, logistical support and methodological advice 
An Analysis of Socio-Economic Strains and Population Gains:

Urban and Rural Communities of Canada: 1981-2001

\section{End Notes:}

In structural equation models, the likelihood ratio statistic measures the difference between implied and observed covariance matrices and is approximately distributed with degrees of freedom equal to $1 / 2(p+q)(p+q+1)-t$, where $p$ and $q$ are observed endogenous and exogenous indicators and $t$ is the total number of independent parameters estimated in the model. The Steiger-Lind RSMEA index or root mean square of approximation is a measure of discrepancy between functions calculated between population and sample moments and it is used to compare models. Ideal RMSEA indices do not generally exceed the .10 value.

It should be noted that six standardized parameters of the QSEM models in urban and rural communities presented unusual $\mathrm{R}^{2} \mathrm{~s}$ for strain-to-strain paths (higher than 1). Estimates could have been possibly affected by fluctuations in the expected time decay of covariances between strain indicators across time notably by unemployment indicators. Despite these shortcomings, however, strain-to-strain paths remained relatively stable and observed positive across the five census observation points.

\section{References:}

Agnew, R. 1999. “A General Strain Theory of Community Differences in Crime Rates" by Agnew, R., Journal of Research in Crime and Delinquency", 36: 123-155.

Alasia, A. and Rothwell,N. 2003. "The Rural / Urban Divide is Not Changing: Income Disparities Persist", Rural and Small Town Canada Analysis Bulletin Vol. 4, No. 4. Ottawa: Statistics Canada, Cat. 21-006-XIE.

Alasia, A. 2003. "Sub-provincial Income Disparity in Canada: Evidence from 1992 to 1999", Ottawa: Statistics Canada, Agriculture and Rural Working Paper No. 63, Cat. 21-601-MIE.

Arbuckle ,J. L. and Wothke, 1999. Amos 5.0. Users Guide, SPSS Inc.

Bollen K. A. and Long, J. S .1993. Introduction: Testing Structural Equation Models. Sage: Newbury Park, California, pp. 1-21.

Bourne, L. S and Simmons, J. 2002 ."New Faultlines: Recent Trends in the Canadian Urban System and their Implications for Planning and Public Policy", Department of Geography and Program in Planning, University of Toronto, Canadian Journal of Urban Research, 12: 1 sup. pp. 22-47. 
Fernando Mata and Ray D. Bollman

Du Plessis, V., Beshiri, R. Bollman,R.D and Clemenson, H. 2001 "Definitions of Rural”, Rural and Small Town Canada Analysis Bulletin Vol. 3, No. 3. Ottawa: Statistics Canada, Catalogue, no. 21-006-XIE.

Hagan, J. 1994. Crime and Disrepute, Thousand Oaks: Pine Forge Press.

Feser, E. and Sweeney, S. 2003. "Out-migration, Depopulation and the Geography of U.S. Economic distress”, International Regional Science Review 26: 38-67.

Joreskog, K.J. 1970. Estimation and Testing of Simplex Models" British Journal of Mathematical and Statistical Biology 23: 121-145 .

Lee,K.2000. "Urban Poverty in Canada: A Statistical Profile Source”, Canadian Council for Social Development Publication, Ottawa.

Mwansa,P.B. and Bollman,R.D. 2005 "Community Demographic Trends Within their Regional Context”, Statistics Canada, Rural and Small Town Canada Analysis Bulletin, 6: 3.

OECD (Organisation for Economic Co-operation and Development). 1994. "Creating Rural Indicators for Shaping Territorial policy / Créer des indicateurs ruraux pour étayer la politique territoriale", Paris: Organization for Economic Cooperation and Development.

PRI (Policy Research Initiative). 2004. “A Life Course Approach for Policy Analysis: A Proposed Framework”, PRI Discussion Paper.

Shearmur,R and Polese,M. 2001. “Economic Development in Canadian Peripheral Regions, 1971 to 1999: A Statistical Overview”, Montreal: INRS (l'Institut national de la recherche scientifique) Publication.

Statistics Canada. 2002. 2001 Census Dictionary, Ottawa: Statistics Canada, Catalogue no. 92-378.

Wheaton,B., Muthen,B., Alwin, D. and Summers, G.F . 1977. "Assessing Reliability and Stability in Panel Models" in Heise, D.R.(Ed).

Sociological Methodology, San Francisco: Jossey Bass. pp. 84-136. 
An Analysis of Socio-Economic Strains and Population Gains: Uban and Rural Communities of Canada: 1981-2001

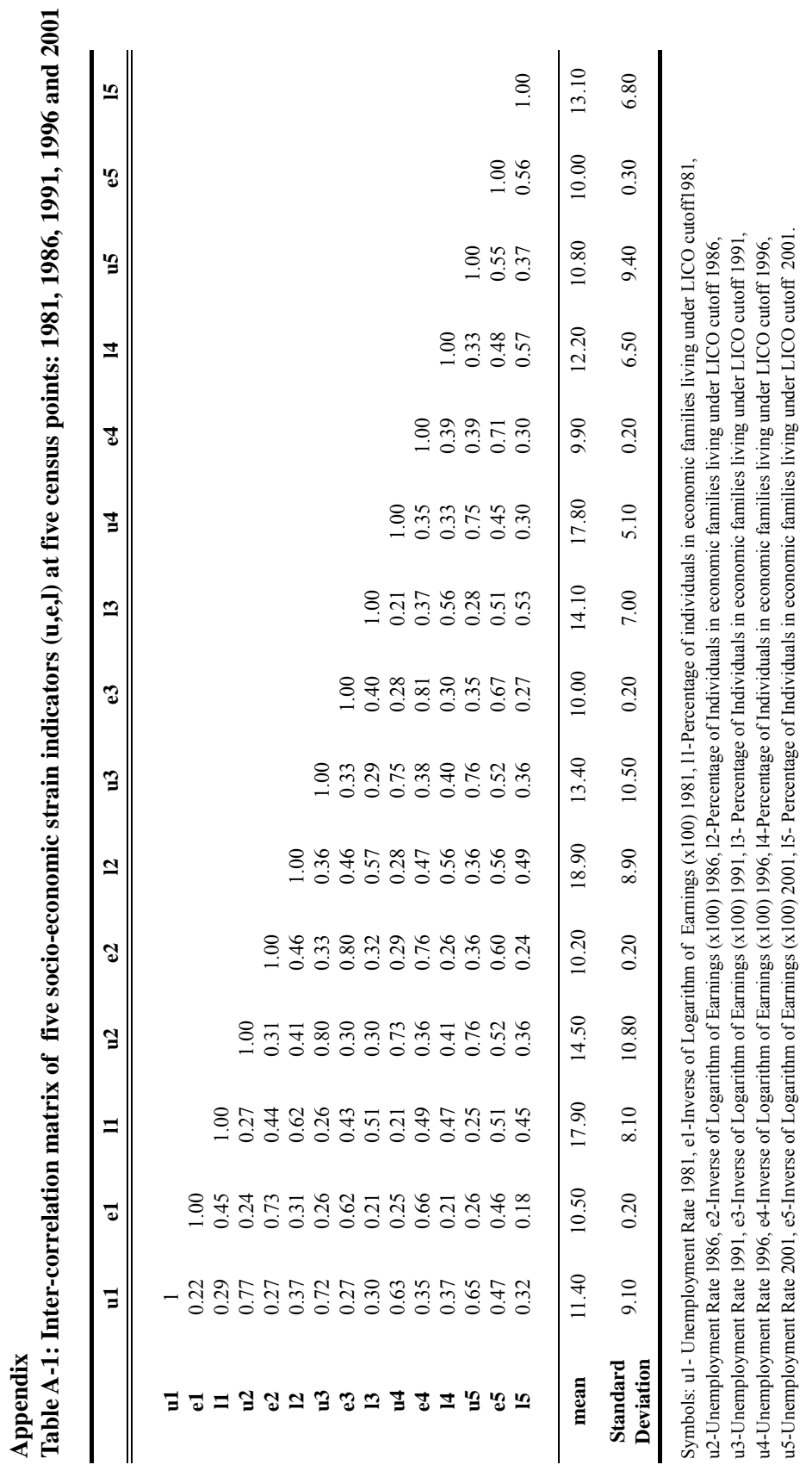

